\title{
Benzodiazepines Dependence: Addiction to Legally Prescribed Substances
}

\author{
Sofia S. Anna Gandra ${ }^{1^{*}}$, Agostinho Leite D’ Almeida², Zélia M. Teixeira ${ }^{3}$ \\ ${ }^{1}$ Psychologist and Jurist, Anibal Pinto $\mathcal{E}$ Associados, S. Mamede de Infesta, Portugal; ${ }^{2}$ Psychologist, ISMAI - University College of Maia, \\ Maia, Portugal; ${ }^{3}$ Psychologist, UFP - Universidade Fernando Pessoa, Porto, Portugal
}

\begin{abstract}
The undue use of benzodiazepines can lead to dependence of this substance, constituting a serious health problem, hard to manage therapeutically. Despite this finding, the prescription of benzodiazepines is still common. In the literature there are several proposals for therapeutic intervention, ranging from the gradual reduction to the psychotherapeutic intervention. In view of the above, this review of the literature aims to understand the specific theme of addition to benzodiazepines. With the present study, we highlight the impact that this dependence has on individuals' lives, the difficulty of withdrawing these substances, and the lack of adequate responses in the national health system to deal with the problem. We came to the conclusion that the psychotherapeutic intervention is extremely important for the treatment of this phenomenon and that the prevention of these situations must be a priority.
\end{abstract}

Keywords: Benzodiazepines; Addiction; Withdrawal

\section{INTRODUCTION}

In 2016, the Portuguese Observatory of Health Systems [1] (p. 65) stated that "Without wanting to diabolize this pharmacological class, useful and necessary, it is necessary to assume the existence of a public health problem in the prescription of benzodiazepines", and thus alerted to a growing problem in the health field - increased excessive and inappropriate prescription and the consequent misuse of benzodiazepines (BZDs) [2].

Since its inception, about 50 years ago [3,4], BZDs have become a widely prescribed drug for a variety of conditions, especially anxiety and insomnia [5-12] given their efficacy and speed in controlling anxious symptoms [3,4]. Anxiety is a highly prevalent and disabling problem [13-15], particularly in its dimension defined as Generalized Anxiety Disorder (PAG), which is one of the most common and limiting chronic mental disorders [16-18].

Despite the evidence of the psychotherapeutic intervention in anxiety, namely Cognitive-Behavioral Therapy (CBT) [19-22], anxious patients are more likely to choose pharmacotherapy than psychotherapy [23-25]. However, the use of pharmacotherapy, specifically the use of BZDs requires a number of precautions [26], since they are only safe and effective for short-term treatment, and its long-term use may lead to development of tolerance and dependence $[3,5,6,9,11,26,27]$ and to be able to present countless consequences and undesirable effects [5,9,12,18,25,28-31].

However, although there are several therapeutic possibilities for its management and treatment [5,10,28,32], none have been particularly effective [9]. It should be added that many of the patients are not recognized or treated, which is disappointing [17]. The present article results from a set of questions that have arisen from the clinical practice of the authors.

\section{LITERATURE REVIEW}

\section{Anxiety - Disturbance and symptoms}

Anxiety disorders are a class of psychiatric disorders that are highly prevalent and disabling [13-15,33]. Most develop during childhood with a tendency to persist into adulthood if they are not treated properly $[17,18]$. Nevertheless, anxiety is a symptom also prevalent in most other psychiatric disorders [15], especially in mood disorders in depression [18].

Correspondence to: Sofia S. Anna Gandra, Psychologist and Jurist, Anibal Pinto \& Associados, S. Mamede de Infesta, Portugal, Tel: +220963492; E-mail: sofiasant.annagandra@outlook.com

Received: July 03, 2019; Accepted: July 15, 2019; Published: July 22, 2019

Citation: Sofia SAG, Agostinho LDA, Zélia MT (2019) Benzodiazepines Dependence: Addiction to Legally Prescribed Substances. J Foren Psy. 4:149. doi:10.35248/2475-319X.19.4.149

Copyright: (C) 2019 Sofia SAG, et al. This is an open-access article distributed under the terms of the Creative Commons Attribution License, which permits unrestricted use, distribution, and reproduction in any medium, provided the original author and source are credited. 
According to WHO [34], anxiety disorders rank sixth in the list of most common mental disorders, because they are highly prevalent in the population, and incapacitating, since they cause generalized health losses and the quality of life of the individual $[16,17,35]$.

\section{Therapeutic approach to anxiety}

Psychotherapeutic approach to anxiety: In recent years, there has been a doubling of the number of studies examining the effects of psychotherapies, particularly for Generalized Anxiety Disorder (GAD) in adults $[19,22]$. In this sense, we have found several studies, systematic reviews and meta-analyzes that demonstrate CBT as an effective treatment for PAG $[3,19,22,36]$, and is also validly validated for the treatment of anxiety disorders in children and young people $[37,38]$, thus being referred in a metaanalysis, psychotherapy as a preferred non-pharmacological therapy

for the treatment of anxiety.

CBT is an empirically validated psychotherapy, its collaborative, active, and structured approach based on principles of learning theory combining verbal interventions and behavior modification techniques to help patients identify errors in thinking and [20], to allow a change in cognitive processes and maladaptive behavior in order to reduce psychological distress $[20,39]$. At the level of anxiety intervention, CBT proposes a set of integrated approaches, namely psycho-education and training coping strategies to deal with and deal with anxiety, relaxation, cognitive restructuring and exposure therapy to anxiety stimuli among other techniques [40]. Like CBT, there are other psychotherapies that prove to be effective, as is the case of brief psychodynamic psychotherapy that leads to significant, broad and stable improvements in relation to symptoms of anxiety and depression, and in this comparative study there were no differences with TCC [21].

\section{Pharmacological approach}

Eager patients are more likely to choose pharmacotherapy than psychotherapy [22,25]. In this context, the drug that appears soon is the benzodiazepines (BZDs) that are widely prescribed for the treatment of anxiety $[5,7,9,10,11,41]$. Since the onset of benzodiazepines, about 50 years ago, they have become the drug of choice for the treatment of anxiety disorders, since they are a medically effective in controlling anxious symptoms, as well as offering quick relief in a short time $[3,4]$. For these reasons, possibly, the use of BZDs has been extended to situations other than the pure pictures of anxious symptomatology. For example, we find references to its use in concomitant depression, alcohol withdrawal among others [42]. However, for several years BZDs are no longer recommended as first-line drugs for the treatment of anxiety disorders, since they involve the risk of causing addiction which has stimulated the development of alternative drugs such as buspirone, antidepressants, among others [4].

In the case of antidepressants, these have a much broader range of indication than the name suggests, and can be used in the treatment of anxiety and stress-related disorders, and several evidences are documented in this sense [43], in particular selective serotonin reuptake inhibitors (SSRIs) and selective noradrenaline reuptake inhibitors (SNRsI) [7].

A review of several studies conducted in 2008 [14] found a number of evidences suggesting new horizons for drug therapies of anxiety disorders, such as corticotropin receptor antagonists, pharmacological blocking of memory-enhancing effects of stress hormones such as glucocorticoids and noradrenaline, glutamate receptor antagonists, glutamatergic receptor agonists, among others that present as an initial promise in preclinical and / or clinical research [43].

The specificity of benzodiazepine treatment: The BZDs were discovered in 1930 by Leo Stemback, however only in 1957 they were introduced in clinical practice [44] through chlordiazepoxide (Librium), promoted as a tranquilizer insurance for emotional problems, having marked a new era of psychopharmacology [24]. Since its introduction in the early 1960s, BZDs are widely used in clinical practice, with a prominent place in medicine, and are the most successful drugs ever for the pharmaceutical industry [28,43], especially in primary health care [23].

In addition, the number of prescriptions has increased exponentially over the past 20 years [28]. Currently, four BZDs are listed among the 100 most commonly prescribed medications: alprazolam clonazepam, diazepam and lorazepam [11,26,45], notably alprazolam, which is the second most popular medication in the world $[28,45]$.

The 2015 annual report of the International Narcotics Control Board [46] states that in Europe, between 2011 and 2013, the total production of 5,441 billion daily doses of benzodiazepines of the sedative, hypnotic, and the production of 12.5 billion daily doses of anxiolytic type benzodiazepines. The consumption figures are similar to those of production. In the year 2013, the most produced anxiolytic benzodiazepines were Alprazolam (41.1\%), Diazepam (about 23.2\%) and Lorazepam (16.6\%).

In Portugal, the use of benzodiazepines has increased, being one of the highest in the world, reaching in 2010 the second position, probably due to its excessive and inappropriate prescription [2]. National data point to a higher prevalence of lorazepam than diazepam [47]. These data are of concern since lorazepam is about ten times more potent than diazepam, being more potently bound to the receptor, which is associated with having a shorter half-life, making its withdrawal more difficult [31].

The popularity of these substances has increased very rapidly, largely because their main function is to reduce subjective tension and induce calm [24,45]. From the 1970s and 1980s BZDs became widely used because of the increased margin of safety and therapeutic efficacy compared to other substances such as barbiturates previously used as anxiolytics [5,24]. As they generally produce immediate effects and are therefore optimal to be prescribed in the short-term treatment $[5,6,26]$. In this sense, they began to be widely prescribed for a variety of conditions, particularly anxiety and insomnia $[5,24,44,45]$.

In the present study, the results of this study are presented in Figure 1. In addition to the anxiolytic and sleep inducing action, and since they reduce neuronal excitability, they are also used for other clinical purposes [27,44], namely hypnotics, anticonvulsants, muscle relaxants, sedation and the use of a single-dose, preoperative, among other uses [5,9,11,25,27,30,43,44].

As to their pharmacokinetic property, BZDs are generally well absorbed orally, but when injected intramuscularly vary in their rate of absorption [7]. The BZDs also differ in their potency and half-life $^{1}$, and may be short, medium or long term [11], and the

$1 \quad$ The half-life is defined as the amount of time required for the

concentration of the substance in the body to decrease by up to $50 \%$. Since the substances do not have the same half-life, so the number of times that one has to 


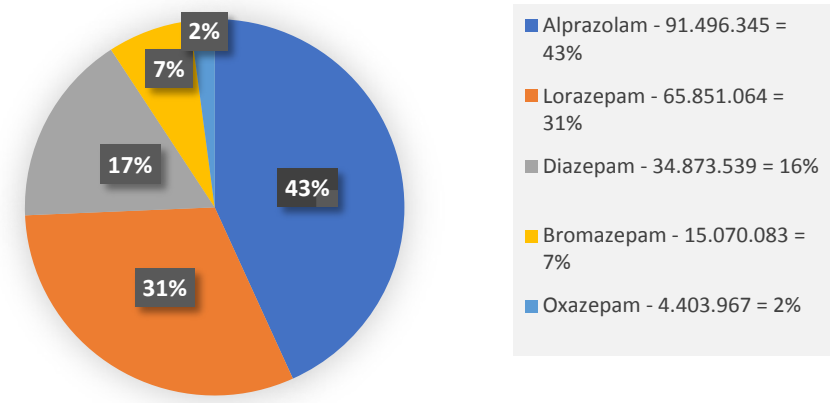

Figure 1: Daily defined doses (DDD) consumed, by international common name (INN) in Portugal in 2014 [47].

longer the half-life, the lower the potency of the drug [31,48], BZDs have a greater potential for dependence than long-term BZDs $[9,43]$.

Although BZDs are effective in a wide range of medical conditions, they require several precautions in their use [26]. When they were introduced into clinical practice, BZDs were thought to have advantages in reducing anxiety without any potential for physical dependence, however the latter claim proved to be unfounded $[5,41]$, since the long-term use is controversial because of the possible development of tolerance and dependence $[3,5,6,9,11,26,27]$.

According to two reviews of several studies the prevalence of longterm use in the general population is approximately $2 \%$ to $7 \%$ $[3,10]$, being widely perceived in most studies as inadequately [3]. As such, many public and psychiatric associations have expressed concern about the possible over prescription of this group of drugs, alerting to the risk of serious side effects, as well as to the production of addiction, especially in BZD with short half-life $[3,5,44]$.

In this sense, the recommendations mention that the prescription of BZDs should be based on careful consideration of the risks and benefits of these and of consideration of probable alternative interventions [26,49,50], just as it should be for some patients and for short and limited time $[9,29,31]$.

The literature mentions that the risk-benefit ratio of benzodiazepine use remains positive in most patients in the short term (2-4 weeks), but is not established beyond this time, mainly due to the difficulty in preventing the short-term and the risk of dependence $[5,7,25,49]$. Despite the recommendations mentioned to limit the use of BZDs, it does not seem to have been met or often ignored $[3,5,24]$, as verified in a meta-analysis where found that the longterm prescription of BZDs is quite common, despite warnings from various medical and health regulators about the risks of such use, such as dependency $[3,5]$.

One possible explanation is that existing guidelines and recommendations are extremely vague and do not assist inexperienced doctors in prescribing or withdrawing BZDs [50]. In addition to the risk of dependence, there is much evidence that long-term use is dangerous $[5,28,50]$. The review of several studies $[5,7,9,12,18,25,28,29,30,51]$, and the most frequent and common risks and effects of the various benzodiazepines, we find that they can be psychological, such as agitation, hallucinations, aggression, anxiety, depression, hostility, irritability, learning

take varies, so the shorter the half-life, the more often one has to take the substance to maintain a stable concentration in the organism, this frequency of taking is translated into a greater probability of dependence [48,31] difficulties, delusions, loss of inhibition, psychosis, dependence, neurological disorders such as anterograde amnesia, ataxia (movement disorders), confusion, disorientation, decreased ability to react, memory impairment, speech disturbances, reduced alertness, delirium, (headache), dizziness (headache), numbness of sensation, fatigue, muscle weakness, light intolerance, constipation, drowsiness, drowsiness, drowsiness, dizziness, dizziness, dizziness, nausea, sedation, visual disturbances changes in appetite, tremors. In some cases, there may also be a risk of morbidity and mortality from both overdose and drug withdrawal $[5,28]$.

The elderly are one of the highest risk groups, with a high prevalence of BZD [45], being the most sensitive to the potential side effects of BZDs [3,30,52] because of cognitive impairment, memory problems, the possibility of dementia, psychomotor deceleration, insomnia, falls and fractures $[5,28,50]$. However, older people are more resistant to leaving this substance, since they believe they cannot afford to stop using it [12].

Although BZD prescribing continues to be important in the context of substance abuse treatment [41], the truth is that special caution should be exercised, since in this population group the prevalence of abuse, abuse and BZD dependence is substantially higher than in the general population [18].

However, there are also those who also use BZDs for recreational purposes and to potentiate the effect of other substances, which in turn increase the effect of dependence and is associated with a pattern of polydrug use $[5,10,53,54]$. In In fact, there is frequent comorbidity between BZD dependence and other disorders due to the use of substances such as alcohol and illicit drugs [5,18,53]. As early as 1967, the potential abuse of benzodiazepines was admitted, and the media alerted to their illicit and non-medical use, especially by the younger population and groups with deviant behaviors [45].

Nowadays the availability of benzodiazepines on the internet as well as from illegal sources has increased its use as "self-medication" in the general population, which is often unaware of its adverse effects and potential addiction, making misuse This availability has also led to the use of benzodiazepines in multiple drug users $[55,56]$. The moral responsibility, which in the previous paragraphs would be the user, being himself to self-medicate inappropriately and abusively, will have to be transferred to the prescribing doctor, and can become talk about inadequate prescription and / or abuse of prescription $[5,7,25,55,57,58]$.

\section{Benzodiazepine dependence}

The misuse and dependence of BZDs has become a serious health problem [6,59], clinically recognized [32], so it is a matter of general concern for health professionals, patients and regulators [3]. It is fundamental to understand, prevent and intervene in this problem [28], thus becoming the addictive behavior of modern times, alongside others.

In order to understand how addiction works, several studies point out that a variety of substances that are consumed in excess and in a way that leads to direct activation of the pathways of the reward system of the brain, namely the mesolimbic/mesocortical dopaminergic system, which is involved in reinforcement of behaviors and in the production of memories [9,11,18,60-62]. That is, there are biological mechanisms in the brain responsible for the wide variety of sensations, namely the sensations of pleasure that mediate the reward experience. By using certain substances, one of these pleasure sensations is activated, causing the individual to 


\section{become dependent on drugs $[9,11,60,63]$.}

Recent literature shows that BZDs have all the hallmarks of addictive drugs [5]. BZDs are a group of sedative, hypnotic and anxiolytic substances that work with depressants of the central nervous system and are capable of producing various disorders of use and dependence $[18,64]$. In this context, the DSM 5 Interactive Classification states that disruption by use of sedatives, hypnotics or anxiolytics is a problematic pattern, leading to clinically significant impairment or distress. BZD dependence is then a condition resulting from repeated use of benzodiazepine substances, which may include both physical and psychological dependence and is characterized by increased substance tolerance or a withdrawal syndrome after dose reduction or abrupt withdrawal of the substance $[24,25,45,61,65,66]$, and also a review of the findings of this paper.

To better understand how the BZD withdrawal syndrome leads to dependence, we must take into account its symptoms, namely rebound anxiety ${ }^{1}$, insomnia, nausea, seizures, panic attacks, muscle cramps, weight loss, memory difficulties and concentration, restlessness, palpitations, as well as some more specific ones such as perceptual distortions, depersonalization, hallucinations, excitability, body image distortion, hypersensitivity, and psychotic symptoms $[5,10,45,48,51]$.

We call special attention to rebound anxiety, which consists of a transient syndrome in which the anxiety symptoms that led to benzodiazepine treatment return more intensively, and may occur at the time of discontinuation of the drug, and the risk is greater if the treatment interruption is abrupt [5].

Although it is a transitory experience, the individual, with despair or fear-induced, immediately recruits the same drug to stop the symptoms, thus maintaining the cycle of dependence $[5,6,10,24,48,61]$. Thus, prolonged use of benzodiazepines rather than reducing anxiety alone is likely to prevent only withdrawal symptoms of this substance [5], a process due to the negative reinforcement associated with a reduction in withdrawal symptoms [25]. This reinforcement supports the belief among patients that benzodiazepines appear to be a necessary evil in the long run [3].

Developmental dependence of BZDs is a predictable phenomenon, influenced by a variety of factors, such as dose, duration of treatment, and a host of other conditions, including individual characteristics [27]. In the literature review, BZD dependence was associated with sociodemographic factors (female gender, low age, lower education and retirement), psychological and psychiatric factors (depression, anxiety, use of antidepressants, hostility, difficulties in getting help to deal with emotional problems and lower quality of life), physical factors (somatization, treatment for dependence, use of other drugs) and factors related to the use of BZD (high daily dosage, prolonged use of BZD, short half-life of BZD, and concomitant use of several BZDs) [8].

In the same line, as risk factors for the dependence of BZDs, we find the following: impulsivity, neuroticism, introversion, search for novelties, environmental factors, availability and clinical maladministration of this substance, presence of other mental

2 Also called "rebound", it is a transient syndrome in which the symptoms that led to the treatment with benzodiazepines return but in an intensified form, being able to occur at the time of discontinuation of the drug, being the greater risk if the interruption of the treatment is abrupt. Although it is a transient syndrome, the individual with despair immediately resorts to the same drug to stop the symptoms, so a cycle of dependency is maintained [5]. disorders such as depression and anxiety, or by use of other substances, negative mood, feelings of inadequacy, indignity and guilt, genetic predisposition or vulnerability to addiction, variations in prescription patterns and availability of this substance in the various countries, course of treatment, lack of clear information given to the patient about the possibility of dependence, lack of use of other alternative treatment methods (psychotherapy), greater use of coping strategies emotional character, history marked a greater accumulation of adverse events prior to treatment or inadequate prior treatments $[8,18,25,58]$.

According to Ashton [5] it is important to highlight three overlapping types of groups of dependents of BZDs. Therapeutic dose dependents, which correspond to most patients who use BZDs in the long run and have inadvertently become dependent as a result of regular repetition over months or years [5]. Another group that is probably dependent are patients with institutionalized physical and psychiatric illnesses and seniors who maintain longterm prescription. Finally, there are those dependent on high-dose prescriptions, a minority of patients who began to escalate dosage excessively, even after the recommended maximum doses, and who do so intentionally [5].

\section{Treatment of benzodiazepine dependence}

Pharmacotherapeutic intervention: The treatment of BZD dependence is complex, and it is commonplace to emphasize the difficulty of withdrawal in some patients, which may deter some doctors from even trying [50]. International guidelines go in the opposite direction since there is currently evidence that it is possible for most people to successfully withdraw their dependency on BZD [50], and the results show that physical, mental and cognitive performance improves after withdrawal, especially in elderly patients [5].

Management and treatment of BZD dependence involves a gradual withdrawal of this substance, maintenance treatment by antagonist or agonist with equivalent long half-life dose, and/ or by psychological interventions $[5,10,28,32]$. However, until at least 2013, there was no validated treatment for BZD dependence [9]. Approaching the rate of reduction of BZD dosage varies for different types of individuals and should be gradually decreased, because abrupt withdrawal especially at high doses can precipitate convulsions, acute psychotic states and other serious reactions $[5,28]$. As such, the benzodiazepine dosage should be decreased at an individually titrated rate, which should generally be under the patient's control, and the whole process may take weeks or months [69]. Diazepam has been shown to be the ideal substitute for the benzodiazepine phase-down scheme, because it is a long half-life benzodiazepine and a rapid rate of absorption, with a milder reduction in blood levels [5,67-69].

Many substances have been investigated for their ability to attenuate benzodiazepine withdrawal symptoms, but none have proven to be globally useful for dependent patients [5]. For example, nonbenzodiazepine GABA agonists relieve abstinence symptoms, but are contraindicated since they have the same disadvantages as benzodiazepines [5]. Another possibility is the treatment with antagonists, which has shown promising results, namely flumazenil $[10,24,45]$. Flumazenil is a BZD antagonist of the GABAA receptor, with preliminary evidence that its use helps to reduce the withdrawal symptoms of BZDs [24]. Despite some evidence supporting the use of flumazenil infusions to treat benzodiazepine dependence, current guidelines still favor gradual discontinuation 
until total abstinence from BZD [32].

There are also some references that hold that antidepressants, b-adrenoreceptor blockers, gabapentin (and pregabalin) and anticonvulsants help in the management of withdrawal symptoms of BZDs [24]. Another possibility is replacement therapy with longacting BZDs. In a case study with a patient diagnosed with anxiety disorder, the substitution therapy with clonazepam, a slow-onset and long-term BZD for treatment, led to a remarkable improvement in the clinical situation, including cessation of desire, absence of withdrawal symptoms, reduction of anxiety, improvements in social functioning and a better cognitive level [9].

\section{Psychotherapeutic intervention in dependence on benzodiazepines}

As careful as dose reduction is concerned, benzodiazepinedependent patients may develop numerous symptoms. CBT has been identified as a psychotherapy to manage and prevent BZD reduction or withdrawal, promoting successful outcomes $[20,24]$, helping to minimize or deal with withdrawal symptoms [24], as well as helping to prevent relapse [20].

According to a review of several studies the success rate of psychotherapy in managing withdrawal of BZDs is $70-80 \%$ [5]. In this sense, the withdrawal plan should include provision for psychological support, promoting effective management of anxiety and prevention of relapse $[5,69]$. The degree of psychological support required during withdrawal is variable and can range from a single referral to formal CBT or other therapies directed toward anxiety or development of coping strategies to deal with stress [5].

Despite all the above evidence, in some cases pharmacological and psychological interventions have only limited benefit, so some people will not be able to stop using BZDs [50]. In this case, the maintenance of long-term treatment may be considered desirable [50].

Another important aspect to consider is relapse rates between 1 and 5 years after withdrawal varying between 8 and 57\% [5]. The most common causes for relapse in BZD use include experiencing and not knowing how to manage negative emotions or states (e.g., anxiety) without the use of substances, exposure to the substance, unbalanced lifestyles, social pressures to use, and lack of social support [70].

\section{DISCUSSION AND CONCLUSION}

After reviewing the literature for the present study, it was reinforced the finding that this dependence has a considerable weight in the life of the individuals, and for this reason it becomes pertinent to understand the additive behavior sustained in the use of prescribed substances.

This dependence causes physical, psychological and social changes in the life of the dependents, having as main obstacle to the withdrawal of benzodiazepines to rebound anxiety.

We conclude that with careful prescription and medical follow-up, individuals may benefit from the effects of this medication, however, as we have seen, Anxiety Disorder is a chronic disease requiring long-term treatment, or BZD use for more than the time advised by the literature, produces nefarious results, so the choice of these should be limited, and always accompanied by psychotherapeutic intervention, namely Cognitive-Behavioral Therapy.
The psychologist, in this context, has a very important role, since it can help the individual to develop competences in order to face their dependence, and in the treatment of anxiety, and for this, it must intervene in the beliefs, cognitions, expectations and supportsources. It should also help to alleviate the anxiety present, and participate in the concerted strategies for the withdrawal of benzodiazepines. As a solution to the need for caution in the prescription as well as the sale of benzodiazepines, we can use the example of the prescription law in the United States of America (USA], 21 US Code $\S 829$, this control being governed by Federal Food, Drug, and Cosmetic Act.

In the specific case of Alprazolam, and all benzodiazepines, they are classified as Schedule IV (classification from V to I, in order of increasing probability of "abuse"). The "Schedule IV" classification makes prescription and distribution in pharmacies more controlled and regulated, but allowed, because there is justified medical use, and "refills" are allowed (several simultaneous prescriptions to be able to receive the prescription consecutively, but the possession of these controlled substances is only legal with a prescription, thus making it impossible to sell them easily, as well as a greater responsibility of the professionals who can prescribe and sell them.

\section{REFERENCES}

1. Observatório Português dos Sistemas de Saúde. Saúde Procuram-se novos caminhos. Relatório de Primavera 2016. Lisboa: Observatório Português dos Sistemas de Saúde.

2. Lopes R, Yaphe J, Ribas MJ. Prescrição de psicofármacos nos cuidados de saúde primários no Porto: estudo transversal. Revista Portuguesa de Medicina Geral e Familiar. 2014;30:368376.

3. Donoghue J, Lader M. Usage of benzodiazepines: A review. Int J Psychiatry Clin Pract. 2010;14:78-87.

4. Hetem LA, Graeff FG. Transtornos da ansiedade. Brasil: Atheneu Editora, 2005.

5. Ashton H. The diagnosis and management of benzodiazepine dependence. Current Opinion in Psychiatry. 2005;18:249-255.

6. Fresán A, Minaya O, Cortés-López JL, Ugalde O. Características demográficas y clínicas associadas a la dependencia a benzodiacepinas en pacientes psiquiátricos. Salud Mental. 2011;34:103-109.

7. Lader M. Benzodiazepines revisited-will we ever learn? Addiction. 2011;106:2086-2109.

8. Manthey L, Lohbeck M, Giltay EJ, Van Veena T, Zitman FG. Correlates of benzodiazepine dependence in the Netherlands Study of Depression and Anxiety. Addiction. 2012;107:2173. 2182.

9. Maremmani AGI, Rovai L, Rugani F, Bacciardi S, Pacini M, Dell'Osso L, et al. Clonazepam as agonist substitution treatment for benzodiazepine dependence: A case report. Case Rep Psychiatry. Article ID 367594, 2013;1-4.

10. Quaglio G, Pattaro C, Gerra G, Mathewson S, Verbanck P, Des Jarlais DC, et al. High dose benzodiazepine dependence: description of 29 patients treated with flumazenil infusion and stabilised with clonazepam. Psychiatry Res. 2012;198:457-462.

11. Tan KR, Rudolph U, Lüscher C (2011) Hooked on benzodiazepines: GABAA receptor subtypes and addiction. 
Trends Neurosci. 34:188-197.

12. Voyer P, Préville M, Martin LS, Roussel ME, Béland SG, Berbiche D (2011) Factors Associated with Self-Rated Benzodiazepine Addiction among Community-Dwelling Seniors. J Addict Nurs. 22:46-56.

13. Correia DT, Guerreiro DF, Barbosa A. Semiologia psicopatológica. Em D.T. Correia (Ed.), Manual de psicopatologia: De acordo com o DSM-5 (2a ed., pp.19-91). Lisboa: Lidel - Edições Técnicas, Lda, 2014.

14. Mathew SJ, Price RB, Charney DS. Recent advances in the neurobiology of anxiety disorders: Implications for novel therapeutics. Am J Med Genet. 2008;148C: 89-98.

15. Monteiro-Ferreira J. Suicídio e perturbações da ansiedade: qual é o risco? Em C.B. Saraiva, B. Peixoto \& D. Sampaio (Eds), Suicídio e comportamentos autolesivos: Dos conceitos à prática clinica, 327-336. Lisboa: Lidel - Edições técnicas, lda, 2014.

16. Andrews G, Hobbs MJ, Borkovec TD, Beesdo K, Craske MG, Heimberg RG, et al. Generalized worry disorder: a review of DSM-IV generalized anxiety disorder and options for DSM-V. Depress Anxiety. 2010;27:134-147.

17. Lader M. Generalized Anxiety Disorder. Encyclopedia of Psychopharmacology. 2015;699-702.

18. American Psychiatric Association (APA). DSM 5 - Manual diagnóstico e estatístico das perturbações mentais (5th edn). Lisboa: Climepsi Editores, 2014.

19. Dugas MJ, Brillon P, Savard P, Turcotte J, Gaudet A. A randomized clinical trial of cognitive-behavioral therapy and applied relaxation for adults with generalized anxiety disorder. Behavior Therapy. 2010;41: 46-58.

20. Galperyn K, Crockford D, El-Guebaly N. Understanding cognitive behavioural therapy for addiction: Its use in tapering off benzodiazepines. Can J Addict Med. 2014;5:13-15.

21. Moriana JA, Gálvez-Lara M, Corpas J. Psychological treatments for mental disorders in adults: A review of the evidence of leading international organizations. Clin Psychol Rev. 2017;54:29-43.

22. Cuijpers P, Sijbrandij M, Koole S, Huibers M, Berking M, Andersson G. Psychological treatment of generalized anxiety disorder: A meta-analysis. Clin Psychol Rev. 2014;34:130-140.

23. Bagby RM, Psych C, Quilty LC, Ryder AC. Personality and depression. Can J Psy. 2008;53:14-25.

24. Hood SD, Norman A, Hince DA, Melichar JK, Hulse GK. Benzodiazepine dependence and its treatment with low dose flumazenil. Br J Clin Pharmacol. 2012;77:285-294.

25. Konopka A, Pe\ka-Wysiecka J, Grzywacz A, Samochowiec J. Psychosocial characteristics of benzodiazepine addicts compared to not addicted benzodiazepine users. Prog NeuroPsychopharmacol Biol Psychiatry. 2013;40: 229-235.

26. Longo LP, Johnson B. Addiction: Part I. Benzodiazepines - side effects, abuse risk and alternatives. Am Fam Physician. 2000;61:2121-2128.

27. Salzman C. Addiction to benzodiazepines. Psychiatric Quarterly. 1998;69: 251-261.
28. Brett J, Murnion B. Management of benzodiazepine misuse and dependence. Australian Prescriber. 2015;38:152-155.

29. Coutinho D, Vieira DN, Teixeira HM. Condução sob influência de benzodiazepinas e antidepressivos prescrição médica e abuso. Acta Médica Portuguesa. 2011;24:431-438.

30. Gérardin M, Victorri-Vigneau C, Guerlais M, Guillou-Landreat M, Grall-Bronnec M, Jolliet P. Benzodiazepines consumption: Does dependence vary with age? Substance Use \& Misuse. 2014:49:1417-1425.

31. Pires CML. E quando o Rei vai nú: Os problemas e as vítimas das drogas psiquiátricas. Leiria: Editorial Diferença, 2003.

32. Liebrenz M, Schneider M, Buadze A, Gehring MT, Dube A, Caflisch C. Attitudes towards a maintenance (-agonist) treatment approach in high-dose benzodiazepine-dependent patients: a qualitative study. Harm Reduction Journal. 2016;13:1-10.

33. Baldomero EB. Depresion y ansiedad? 100 preguntas mas frecuentes. Madrid: Editores Médicos, S.A, 2001.

34. World Health Organization (WHO) Depression and other Common Mental Disorders: Global Health Estimates. Geneva: World Health Organization, 2017.

35. Spitzer RL, Kroenke K, Williams JBW, Löwe B. A brief measure for assessing generalized anxiety disorder: The GAD-7. Arch Intern Med. 2006;166:1092-1097.

36. Behar E, DiMarco ID, Hekler EB, Mohlman J, Staples AM. Current theoretical models of generalized anxiety disorder (GAD): Conceptual review and treatment implications. J Anxiety Disord. 2009;23:1011-1023.

37. In-Albon T, Schneider S. Psychotherapy of childhood anxiety disorders: A meta-analysis. Psychother Psychosom. 2007;76:15 24.

38. Reynolds S, Wilson C, Austin J, Hooper L. Effects of psychotherapy for anxiety in children and adolescents: A metaanalytic review. Clin Psychol Rev. 2012;32:251-262.

39. Stallard P. Bons Pensamentos Bons Sentimentos. Manual de terapia cognitivo-comportamental para crianças e adolescentes. Porto Alegre: Artmed, 2004.

40. Ito LM. Terapia cognitivo-comportamental para transtornos psiquiátricos. Porto Alegre: Artes Médicas, 1998.

41. Ashworth M, Gerada C, Dallmeyer R. Benzodiazepines: addiction and abuse. Drugs: education, prevention and policy. 2002;9:389-397.

42. Infarmed. Folheto informativo - Alprazolam, 2017 d.

43. Cuevas C, Sanz E, Fuente J. Benzodiazepines: More "behavioural" addiction than dependence. Psychopharmacology. 2003;167:297-303.

44. Rosas-Gutiérrez I, Simón-Arceo K, Mercado F. Mecanismo celular y molecular de la adicción a benzodiacepinas. Salud Mental. 2013;36:325-329.

45. Licata SC, Rowlett JK. Abuse and dependence liability of benzodiazepine-type drugs: GABA(A) receptor modulation and beyond. Pharmacol Biochem Behav. 2008;90:74-89.

46. International Narcotics Control Board. Annual Reports 2015 
- Special Report: Availability of Internationally Controlled Drugs: Ensuring Adequate Access for Medical and Scientific Purpose. New York: United Nations, 2016.

47. Da Saúde DG (DGS 2016). Portugal - Saúde Mental em Números 2015. Lisboa: Direção-Geral da Saúde.

48. Hallstrom C, McClure N. Anxiety and depression: Your questions answered. Edinburgh: Churchill Livingstone, 1999.

49. Zandstra S, Furer J, Van de Lisdonk E, Bor J, Zitman F, Van Weel C. Differences in health status between long-term and short term benzodiazepine users. Br J Gen Pract. 2002;52:805808 .

50. Baldwin DS, Aitchison K, Bateson A, Curran HV, Davies S, Leonard B, et al. Benzodiazepines: Risks and benefits. A reconsideration. J Psychopharmacol. 2013;27:967-71.

51. Breggin PR. Analysis of adverse behavioral effects of benzodiazepines with a discussion on drawing scientific conclusions from the FDA's spontaneous reporting system. The J Mind and Behav. 1998;19:21-50.

52. Bogunovic OJ, Greenfield SF. Practical geriatrics: Use of benzodiazepines among elderly patients. Psychiatric Services. 2004;55:233-235.

53. Ghitza UE, Epstein DH, Preston KL. Self-report of illicit benzodiazepine use on the Addiction Severity Index predicts treatment outcome. Drug Alcohol Depend. 2008;97:150-157.

54. Ashton H. The Ashton manual supplement: A supplement to benzodiazepines: How they work $\&$ how to withdraw, 2011.

55. Tan KR, Brown M, Labouèbe G, Yvon C, Creton C, Fritschy JM, et al. Neural bases for addictive properties of benzodiazepines. Nature. 2010;463:769-774.

56. Weissberg V. 100 perguntas e respostas sobre álcool, drogas e tabaco. Lisboa: Pactor, 2012.

57. Miranda JA. Benzodiazepinas: Usos e abusos. Rev Port Clin Geral. 2000;16:355-357.

58. Zandstra SM, Van Rijswijk E, Rijndersa C, Van de Lisdonk EH, Bor JHJ, Van Weel C, et al. Long-term benzodiazepine users in family practice: differences from short-term users in mental health, coping behavior and psychological characteristics. Family Practice. 2004;21:266-269.

59. Hernandez SH, Nelson LS. Prescription drug abuse: insight into the epidemic. Clin Pharmacol Ther. 2010;88:307-317.

60. Enoch M. The role of early life stress as a predictor for alcohol and drug dependence. Psychopharmacology. 2011;214:17-31.

61. Ouzir M, Errami M. Etiological theories of addiction: A comprehensive update on neurobiological, genetic and behavioural vulnerability. Pharmacol Biochem Behav. 2016;148:59-68.

62. Wise RA. Brain reward circuitry: Insights from unsensed incentives. Neuron. 2002;36:229-240.

63. Tam C, Foo Y. Contributory factors of drug abuse and the accessibility of drugs. Int J Collab Res Intern Med Public Health. 2012;4:1621-1625.

64. Góis M, Amaral J. O uso de drogas lícitas e ilícitas e suas consequências sociais e económicas. ETIC - Encontro de
Iniciação Científica. 2010;5:1-22.

65. Authier N, Balayssac D, Sautereau M, Zangarelli A, Courty P, Somogyi AA, et al. Benzodiazepines dependence: focus on withdrawal syndrome. Ann Pharm Fr. 2009;67:408-413.

66. Bueno JR. Emprego clínico, uso indevido e abuso de benzodiazepínicos - Uma revisão. Debates em Psiquiatria. 2012;3:6-11.

67. Infarmed. Folheto informativo - Diazepam Labesfal, 2017a.

68. Pagliaro LA, Pagliaro AM. The pharmacologic basis of psycotherapeutics: An introduction for psychologists. New York: Brunner/Mazel, USA, 1998.

69. Ashton H. The treatment of benzodiazepine dependence. Addiction. 1994;89:1535-1541.

70.https://www.gpo.gov/fdsys/search/searchresults. action?st=U.S.C. $+353 \% 28 b \% 29$ 